\title{
Atmospheric lifetimes, infrared absorption spectra, radiative forcings and global warming potentials of $\mathrm{NF}_{3}$ and $\mathrm{CF}_{3} \mathrm{CF}_{2} \mathrm{Cl}$ (CFC-115)
}

\author{
Anna Totterdill ${ }^{1}$, Tamás Kovács ${ }^{1}$, Wuhu Feng ${ }^{1,2}$, Sandip Dhomse ${ }^{3}$, Christopher J. Smith ${ }^{4}$, \\ Juan Carlos Gómez-Martín ${ }^{1}$, Martyn P. Chipperfield ${ }^{3}$, Piers M. Forster ${ }^{3}$, and John M. C. Plane ${ }^{1}$ \\ ${ }^{1}$ School of Chemistry, University of Leeds, Leeds, LS2 9JT, UK \\ ${ }^{2}$ NCAS, School of Earth and Environment, University of Leeds, Leeds, LS2 9JT, UK \\ ${ }^{3}$ School of Earth and Environment, University of Leeds, Leeds, LS2 9JT, UK \\ ${ }^{4}$ Energy Research Institute, School of Chemical and Process Engineering, University of Leeds, Leeds, LS2 9JT, UK
}

Correspondence to: Piers M. Forster (p.m.forster@leeds.ac.uk)

Received: 16 March 2016 - Published in Atmos. Chem. Phys. Discuss.: 20 April 2016

Revised: 23 August 2016 - Accepted: 28 August 2016 - Published: 14 September 2016

\begin{abstract}
Fluorinated compounds such as $\mathrm{NF}_{3}$ and $\mathrm{C}_{2} \mathrm{~F}_{5} \mathrm{Cl}(\mathrm{CFC}-115)$ are characterised by very large global warming potentials (GWPs), which result from extremely long atmospheric lifetimes and strong infrared absorptions in the atmospheric window. In this study we have experimentally determined the infrared absorption cross sections of $\mathrm{NF}_{3}$ and $\mathrm{CFC}-115$, calculated the radiative forcing and efficiency using two radiative transfer models and identified the effect of clouds and stratospheric adjustment. The infrared cross sections are within $10 \%$ of previous measurements for CFC-115 but are found to be somewhat larger than previous estimates for NF3, leading to a radiative efficiency for $\mathrm{NF}_{3}$ that is $25 \%$ larger than that quoted in the Intergovernmental Panel on Climate Change Fifth Assessment Report. A whole atmosphere chemistry-climate model was used to determine the atmospheric lifetimes of $\mathrm{NF}_{3}$ and CFC -115 to be $(509 \pm 21)$ years and $(492 \pm 22)$ years, respectively. The GWPs for $\mathrm{NF}_{3}$ are estimated to be 15600 , 19700 and 19700 over 20, 100 and 500 years, respectively. Similarly, the GWPs for CFC-115 are 6030, 7570 and 7480 over 20, 100 and 500 years, respectively.
\end{abstract}

\section{Introduction}

Fluorinated compounds such as $\mathrm{NF}_{3}$ and CFC-115 are potentially important for global warming (Myhre et al., 1998). The stability and thermophysical properties of these gases have made them attractive chemicals for use in many relatively modern industrial processes. $\mathrm{NF}_{3}$ is being used increasingly as a replacement for banned perfluorocarbons (PFCs) which were utilised in processes such as chemical cleaning and circuit etching. It is an extremely potent greenhouse gas with an estimated 100-year global warming potential (GWP) between 10800 and 17000 (Arnold et al., 2013; Robson et al., 2006; Weiss et al., 2008). Weiss et al. (2008) reported a 2008 mean global tropospheric mixing ratio of $0.45 \mathrm{ppt}$ increasing at a rate of $0.053 \mathrm{ppt} \mathrm{yr}^{-1}$. The present-day mixing ratio will therefore be close to $1 \mathrm{ppt}$, assuming no change in emission rate. Arnold et al. (2013) found undetectable levels of $\mathrm{NF}_{3}$ prior to 1975 in archived air samples and ice cores, indicating that the major source of the gas is anthropogenic.

CFC-115 was introduced as refrigerant in the 1970s and prior to this was not detected in the atmosphere. Following the phasing out of CFC-115 through the 1997 Montréal Protocol (Solomon et al., 2007), its atmospheric concentration stabilised by 2005. A mixing ratio of $8.4 \mathrm{ppt}$ was reported

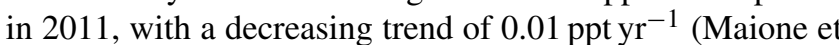
al., 2013). Based on an atmospheric lifetime of 1020 years, its 100-year GWP was estimated to be 7370 (Solomon et al., 2007). 
The change in concentration of any trace gas depends, in part, on how its emission evolves over time, but also on the rates of any chemical and physical removal processes. The only important sinks for CFC-115 and $\mathrm{NF}_{3}$ appear to be photolysis (Dillon et al., 2010; Totterdill et al., 2014, 2015) and reaction with $\mathrm{O}\left({ }^{1} \mathrm{D}\right)$ (Baasandorj et al., 2013; Dillon et al., 2011). Reaction with the meteoric metals $\mathrm{Na}$ and $\mathrm{K}$ is a minor loss route (Totterdill et al., 2014, 2015).

Trace gas concentrations are dependent on the atmospheric lifetimes $(\tau)$ of the species, defined as the ratio of the total atmospheric burden to the total loss rate. Estimates of the atmospheric lifetimes of $\mathrm{NF}_{3}$ and $\mathrm{CFC}-115$ have recently been reported by SPARC (2013). For $\mathrm{NF}_{3}$ the recommended value is 569 years, which was based on 2-D model calculations including loss due to photolysis ( $71 \%$ of total loss) and reaction with $\mathrm{O}\left({ }^{1} \mathrm{D}\right)(29 \%)$. This overall lifetime was slightly larger than the value of 500 years given in the WMO (2011) assessment. For CFC-115, the recommended lifetime is 540 years ( $37 \%$ of loss due to photolysis, $63 \%$ due to reaction with $\mathrm{O}\left({ }^{1} \mathrm{D}\right)$ ), which was much lower than the WMO (2011) value of 1020 years based on the previous $\mathrm{O}\left({ }^{1} \mathrm{D}\right)$ reactive yield from Sander et al. (2011).

Therefore, these fluorinated compounds are very potent global warming agents because, in addition to having atmospheric lifetimes of many centuries, they absorb infrared (IR) radiation strongly between 800 and $1200 \mathrm{~cm}^{-1}$. This region of the electromagnetic spectrum is known as the "atmospheric window" because of a pronounced minimum in atmospheric absorption by $\mathrm{H}_{2} \mathrm{O}, \mathrm{CO}_{2}$ and $\mathrm{O}_{3}$. Furthermore, the window overlaps with the peak in the terrestrial infrared spectrum $\left(500-1500 \mathrm{~cm}^{-1}\right)$, making it a particularly important region in the radiative balance of the atmosphere (Pinnock et al., 1995).

However, it is difficult to quantify surface temperature changes resulting from small perturbations due to climate variability and large uncertainties in climate feedback mechanisms (Pinnock et al., 1995). The historic effects of various drivers of climate change are typically specified and compared in terms of their radiative forcings, a measure of the perturbation to the Earth's energy budget. Various flavours of radiative forcing exist (Myhre et al., 1998). The effective radiative forcing measures top-of-atmosphere energy budget changes following adjustments to the vertical temperature profile, clouds and land-surface temperatures. The stratospheric adjusted radiative forcing is defined as the change in net (i.e. down minus up) irradiance at the tropopause (solar plus longwave, in $\mathrm{W} \mathrm{m}^{-2}$ ) after allowing for stratospheric temperatures to readjust to radiative equilibrium, but with the surface and tropospheric temperatures and state held fixed at the unperturbed values (Ramaswamy et al., 2001). Note the instantaneous radiative forcing (IRF) can be obtained by not applying the stratospheric adjustment. Although effective radiative forcing (ERF) estimates are more representative of temperature changes, they are more uncertain as they rely on climate model estimates of cloud response (Sherwood et al., 2015). Further, climate model radiation codes do not typically represent minor greenhouse gases (GHGs); therefore it is not currently possible to estimate the ERF for the species considered here. We have therefore estimated radiative forcing (RF) and IRF using a line-by-line radiative transfer model (RTM). As the line-by-line RTM only accounts for absorption, the extension to clouds and scattering processes was performed by a secondary radiative transfer model using atmospheric optical depth profiles generated by the RTM.

The purpose of this work was to update the values for the GWPs of $\mathrm{NF}_{3}$ and CFC-115, based on their cloudy-skyadjusted radiative efficiencies (the definition of the GWP is discussed in Section 6) and using a more sophisticated atmospheric model. In order to achieve this, infrared absorption cross sections for both $\mathrm{NF}_{3}$ and CFC-115 were measured and then used as input into the Reference Forward Model (RFM) (Dudhia, 2014) and library for radiative transfer (libRadtran) (Mayer and Kylling, 2005), two radiative transfer models used to calculate radiative forcings and efficiencies. Here, radiative forcing refers to a perturbation of the modern-day concentration of the compound against its pre-industrial concentration, and is given in units of $\mathrm{W} \mathrm{m}^{-2}$. Radiative efficiency refers to a perturbation of $0-1 \mathrm{ppb}$ and is given in units of $\mathrm{W} \mathrm{m}^{-2} \mathrm{ppbv}^{-1}$. The sensitivity of these determined forcings to a number of criteria including cloudiness and stratospheric adjustment was also examined. The atmospheric concentrations of $\mathrm{NF}_{3}$ and CFC- 115 were then determined using the Whole Atmosphere Community Climate Model (Garcia et al., 2007), incorporating the chemical loss processes described in our recent papers (Totterdill et al., 2014, 2015). The Whole Atmosphere Community Climate Model (WACCM) also produced estimates of the atmospheric lifetimes of the two compounds.

\section{Experimental}

The IR spectrum of $\mathrm{NF}_{3}$ has been measured previously by Robson et al. (2006) and Molina et al. (1995), and that of CFC-115 by McDaniel et al. (1991). The cross sections reported in the literature show some scatter, and few quantitative full spectra measurements are available. This work was consequently carried out in order to provide a more complete set of measurements and reduce uncertainty in the published data.

Measurements were made in a $15.9 \mathrm{~cm}$ gas cell sealed with $\mathrm{KBr}$ windows, which allowed transmission between 400 and $4000 \mathrm{~cm}^{-1}$. Spectra were recorded with a Bruker Fourier transform spectrometer (model IFS/66) fitted with a midinfrared source and beam-splitting optics. Room temperature $(296 \pm 2 \mathrm{~K})$ measurements were carried out between 400 and $2000 \mathrm{~cm}^{-1}$ at a spectral resolution of $0.1 \mathrm{~cm}^{-1}$. Absorption spectra were obtained by averaging 128 scans at a scan rate of $1.6 \mathrm{kHz}$. Gas mixtures of different strength were prepared to obtain absorbances with high signal-to-noise ratio, while 
still being within the range of validity of the Beer-Lambert law.

Gas mixtures were made using between 12 and 307 Torr of $\mathrm{NF}_{3}$, and 6 and 77 Torr of CFC-115, made up to 760 Torr with $\mathrm{N}_{2}$. Multiple mixtures were made up so that the cross section could be obtained at a selected wavelength $\lambda$ by taking the slope of the linear regression of the corresponding peak absorbance against concentration according to the Beer-Lambert law:

$A(\lambda)=\sigma(\lambda) l c$

where $A$ is the absorbance, $\sigma$ is absorption cross section in $\mathrm{cm}^{2}, c$ is concentration in molecule $\mathrm{cm}^{-3}$ and $l$ is path length in $\mathrm{cm}$. Concentrations were determined from the mixing ratios calculated from pressures measured with a capacitance manometer (Baratron model $222 \mathrm{CA}$ ), calibrated with an oil manometer. Uncertainties in concentrations are smaller than $1 \%$ are reported in the Results section. Analyte concentrations were selected so that $A<1$, to avoid deviation from the Beer-Lambert linear behaviour. Baseline and background corrections (including removal of $\mathrm{CO}_{2}$ and $\mathrm{H}_{2} \mathrm{O}$ ) were performed after the experiments.

Reactant gas mixtures for the experiments were prepared on all-glass vacuum lines. The gases $\mathrm{N}_{2}(99.9999 \%$, BOC) and $\mathrm{NF}_{3}(99.99 \%, \mathrm{BOC})$ were used without further purification. Samples of CFC-115, provided by Professor William Sturges (University of East Anglia), were purified by freeze-pump-thaw degassing on a glass vacuum line.

\section{Atmospheric modelling}

The atmospheric distributions of $\mathrm{NF}_{3}$ and $\mathrm{CFC}-115$ were simulated using the 3-D WACCM (Garcia et al., 2007). WACCM is a comprehensive numerical model extending vertically from the ground up to the lower thermosphere $(\sim 140 \mathrm{~km})$ and is part of the National Centre for Atmospheric Research (NCAR) Community Earth System Model (CESM) (Lamarque et al., 2012). WACCM calculates the concentrations of atmospheric species by considering all relevant chemical and dynamical processes. Here we have used a free running version of WACCM 4 (Garcia et al., 2007), which has 66 levels from the surface to $5.96 \times 10^{-6} \mathrm{~Pa}(\sim 140 \mathrm{~km})$ with a vertical resolution of $3.5 \mathrm{~km}$ scaled height in the mesosphere and lower thermosphere $(\mathrm{MLT})$ region and $1.9^{\circ} \times 2.5^{\circ}$ (latitude $\times$ longitude) horizontal resolution. The model contains all the important details of the MLT processes including radiative transfer, auroral processes, non-local thermodynamic equilibrium and the molecular diffusion of constituents.

A series of $\mathrm{NF}_{3}$ and $\mathrm{CFC}-115$ tracers were included in the model. For the model simulations presented here, three loss processes for $\mathrm{NF}_{3}$ and $\mathrm{CFC}-115$ were included: reactions with $\mathrm{O}\left({ }^{1} \mathrm{D}\right)$; reactions with the mesospheric metals $(\mathrm{Na}$, $\mathrm{K})$; and UV photolysis. For each compound, a set of five trac- ers was used. One tracer was removed by all three processes; three tracers were used to determine the individual impact of each loss process acting alone; and the fifth was a passive (i.e. chemically inert) tracer. In a recent paper, Papadimitriou et al. (2013) concluded that the 200-220 nm wavelength range is important for $\mathrm{NF}_{3}$ photolysis in the stratosphere. The long-wavelength photolysis cross section also has a strong temperature dependence. In the current study this wavelength region was also included. Two model runs were carried out, without and with the $>200 \mathrm{~nm}$ regime. For CFC-115 only one model run was carried out that included both the short- and long-wavelength absorption cross sections. SPARC (2013) reported that the 190-230 $\mathrm{nm}$ region accounts for $28 \%$ of the total CFC-115 loss.

The relevant rate coefficients for $\mathrm{O}\left({ }^{1} \mathrm{D}\right)$ and the metal atom reactions that were added to the chemistry module in WACCM are listed in Table 1. Note that we have only included the reactions with $\mathrm{Na}$ and $\mathrm{K}$, as the reactions with the more abundant meteoric metals $\mathrm{Fe}$ and $\mathrm{Mg}$ are very slow at temperatures below $300 \mathrm{~K}$ (Totterdill et al., 2014, 2015). The standard chemistry scheme in WACCM contains 59 species and 217 gas-phase reactions (Kinnison et al., 2007). $\mathrm{O}\left({ }^{1} \mathrm{D}\right)$ was determined from this scheme. Modules with a further 61 reactions describing the chemistry of $\mathrm{Na}$ and $\mathrm{K}$ were then added to this scheme, along with the meteoric input functions required to simulate the $\mathrm{Na}$ and $\mathrm{K}$ layers in the MLT (Marsh et al., 2013a; Plane et al., 2014).

The photolysis rates of $\mathrm{NF}_{3}$ and $\mathrm{CFC}-115$ were calculated in WACCM using the fitted expressions we determined previously for their absorption cross sections as a function of wavelength between 121.6 and $200 \mathrm{~nm}$ (Totterdill et al., 2014, 2015). Following the study by Marsh et al. (2013b), the daily solar spectral irradiances used in WACCM were specified from the model of Lean et al. (2005), updated with the total solar irradiance of Kopp and Lean (2011). The model was then run from year 2000 for 13 years when the solar data are available and are enough for the atmospheric lifetimes of $\mathrm{NF}_{3}$ and $\mathrm{CFC}-115$ to reach a steady state. Although timedependent solar forcing was used in the simulations, it does not have any noticeable impact on the very long lifetimes of these gases.

\section{Radiative transfer modelling}

Radiative forcing calculations were made using the Reference Forward Model (RFM) (Dudhia, 2014). The RFM is a line-by-line radiative transfer model based on the previous GENLN2 model (Edwards, 1987), and includes absorption cross sections for CFC-115 and $\mathrm{NF}_{3}$ derived from the HITRAN database (Rothman et al., 2013). In addition to providing upwelling and downwelling longwave fluxes for calculating the clear-sky forcing, the RFM was used to generate optical depth profiles at a resolution of $1 \mathrm{~cm}^{-1}$ for input into the DISORT radiative transfer solver as implemented in the 
Table 1. Metal atom and $\mathrm{O}\left({ }^{1} \mathrm{D}\right)$ reactions with $\mathrm{NF}_{3}$ and $\mathrm{CFC}-115$ added to the WACCM chemistry module.

\begin{tabular}{lll}
\hline Reaction & Rate coefficient/cm $\mathrm{cm}^{3}$ molecule $\mathrm{s}^{-1}$ & Source \\
\hline $\mathrm{O}\left({ }^{1} \mathrm{D}\right)+\mathrm{NF}_{3}$ & $(2.0 \pm 0.3) \times 10^{-11}$ & Dillon et al. (2011) \\
$\mathrm{Na}+\mathrm{NF}_{3}$ & $6.0 \times 10^{-10} \exp (-2240 / T)$ & Totterdill et al. (2014) \\
& $+2.3 \times 10^{-11} \exp (-589 / T)$ & \\
$\mathrm{K}+\mathrm{NF}_{3}$ & $16.0 \times 10^{-10} \exp (-2297 / T)$ & Totterdill et al. (2014) \\
$\mathrm{O}\left({ }^{1} \mathrm{D}\right)+\mathrm{CFC}-115$ & $(6.5 \pm 0.6) \times 10^{-11} \exp (+30 / T)$ & Baasandorj et al. (2013) \\
$\mathrm{Na}+\mathrm{CFC}-115$ & $5.9 \times 10^{-10} \exp (-4257 / T)$ & Totterdill et al. (2015) \\
$\mathrm{K}+\mathrm{CFC}-115$ & $+1.8 \times 10^{-11} \exp (-2093 / T)$ & Totterdill et al. (2015) \\
\hline
\end{tabular}
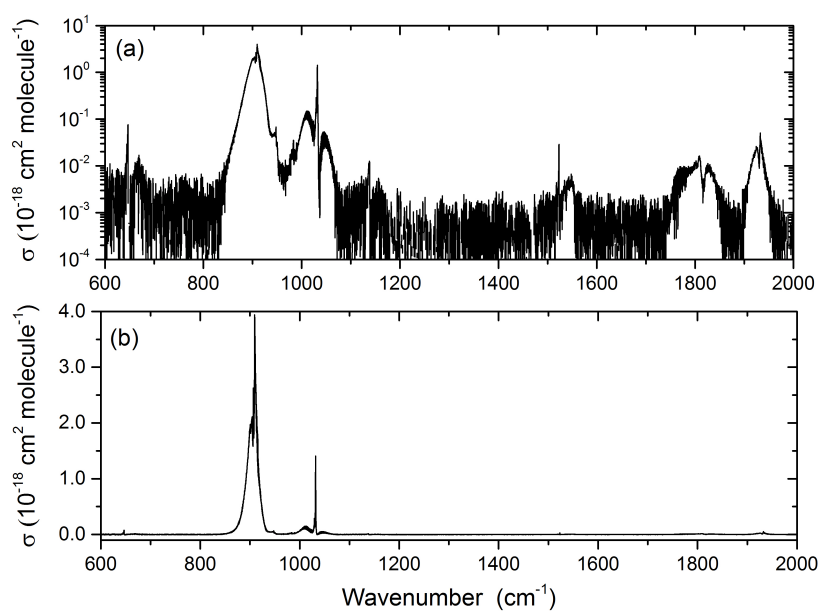

Figure 1. Infrared absorption spectrum of $\mathrm{NF}_{3}$ at $295 \pm 2 \mathrm{~K}$ on a logarithmic (a) and linear (b) scale. The logarithmic plot highlights the minor bands.

libRadtran (Mayer and Kylling, 2005). The clear-sky fluxes obtained from the RFM were validated against results from libRadtran for the cloudless, non-scattering case.

Calculations to obtain the IRF and RF were performed using the flux form of the RFM at a spectral resolution of $0.1 \mathrm{~cm}^{-1}$, determined by the resolution of the IR spectra measured in the present study (Sect. 2). The radiative transfer calculation was performed on each spectral band between 550 and $2000 \mathrm{~cm}^{-1}$, and the irradiance flux was integrated over the wavelength to obtain the net irradiance at each level in the model atmosphere. For these calculations the Planck function was set to vary linearly with optical depth. For the stratospheric adjustment, the stratosphere temperatures were adjusted using an iterative process based on heating rate changes that after 100 days have changed the stratospheric temperatures and returned them to radiative equilibrium (see also in Introduction). For both $\mathrm{NF}_{3}$ and $\mathrm{CFC} 115$ the temperature change at the tropopause is $\sim 1.5 \times 10^{-5} \mathrm{~K}$ for a perturbation of $1 \mathrm{ppt}$ (average tropospheric volume mixing ratio), and $\sim 0.01 \mathrm{~K}$ for a perturbation of $1 \mathrm{ppb}$.
A compilation of line data for background species was obtained from HITRAN 2012 (Rothman et al., 2013), and absorption cross sections for $\mathrm{NF}_{3}$ and CFC-115 were measured in the present study. The temperature, pressure and mixing ratios of the major atmospheric constituents $\mathrm{CO}_{2}, \mathrm{H}_{2} \mathrm{O}, \mathrm{CH}_{4}$, $\mathrm{N}_{2} \mathrm{O}$ and $\mathrm{O}_{3}$, as well as $\mathrm{NF}_{3}$ and CFC-115, were obtained from the WACCM output. The temperature dependence of background species' absorption is automatically interpolated from HITRAN data. Although the temperature dependence of the $\mathrm{NF}_{3}$ and CFC-115 cross sections was not measured, we assume that it makes a negligible uncertainty in the radiative forcing calculations.

The effect of seasonal and geographical variations on factors influencing radiative forcing means that multiple averaged local radiative forcings calculated across the locationtime grid are needed to estimate global forcing. The instantaneous and adjusted radiative forcings and efficiencies were first calculated in the RFM for each month between -90 and $90^{\circ}$, at a $9^{\circ}$ latitude and longitude resolution. We also created vertical profiles by averaging three latitudes (representing the tropics, midlatitudes and high latitudes) for each month. The area-averaged forcing from the three profiles was found to yield a forcing value within $2 \%$ of that obtained from the gridded data. Compared to using a global annual mean profile, Freckleton et al. (1998) demonstrated that the method of averaging a small number of latitudes is 5-10\% more accurate than use of the global annual mean profile. Explanations for this difference in accuracy are discussed in Sect. 5.3. The profiles representing the three latitudes for each month were also used to calculate radiative forcings and efficiencies in libRadtran. Clear-sky IRFs calculated in libRadtran were within $3 \%$ of those calculated by the RFM.

\section{Results}

\subsection{Infrared absorption spectra}

Figure 1 illustrates the IR absorption cross section spectrum measured for $\mathrm{NF}_{3}$ in the present study. The band strengths sections obtained from this measured spectrum are listed 
Table 2. Integrated absorption cross sections of $\mathrm{NF}_{3}$ measured in the present study at $296 \pm 2 \mathrm{~K}(1 \sigma$ uncertainty $\pm 6 \%$ for the major bands), and compared to the previous studies of Robson et al. (2006) and Molina et al. (1995).

\begin{tabular}{|c|c|c|c|}
\hline $\begin{array}{l}\text { Band limits/ } \\
\mathrm{cm}^{-1}\end{array}$ & $\begin{array}{r}\text { Integrated IR band } \\
\text { cross section/ } \\
10^{-18} \mathrm{~cm}^{2} \mathrm{molec}^{-1} \mathrm{~cm}^{-1}\end{array}$ & $\begin{array}{l}\text { Ratio to } \\
\text { integrated } \\
\text { cross section } \\
\text { from Robson } \\
\text { et al. (2006) }\end{array}$ & $\begin{array}{l}\text { Ratio to } \\
\text { integrated } \\
\text { cross section } \\
\text { from Molina } \\
\text { et al. (1995) }\end{array}$ \\
\hline $600-700$ & 0.41 & 1.06 & 1.20 \\
\hline $840-960$ & 65.03 & 1.03 & 1.79 \\
\hline 970-1085 & 5.88 & 1.11 & 1.39 \\
\hline $1085-1200$ & 0.10 & 0.66 & 0.68 \\
\hline $1330-1440$ & 0.08 & 4.35 & 4.76 \\
\hline $1460-1580$ & 0.21 & 1.54 & 1.59 \\
\hline $1720-1870$ & 0.71 & 0.97 & 1.09 \\
\hline $1890-1970$ & 0.65 & 1.01 & 1.06 \\
\hline $600-1970$ & 73.50 & 1.04 & 1.72 \\
\hline
\end{tabular}

in Table 2, which are also compared with the integrated cross sections reported in the literature, where available. Similarly, the CFC-115 spectrum is displayed in Fig. 2, and Table 3 lists the corresponding integrated cross sections and comparison with the literature. The uncertainties in the sample concentrations of $\mathrm{NF}_{3}$ and CFC-115 were \pm 0.8 and $0.7 \%$, respectively. The average spectral noise was $\pm 5 \times 10^{-21} \mathrm{~cm}^{2}$ molecule ${ }^{-1}$ per $1 \mathrm{~cm}^{-1}$ band. However, at wavenumbers $<550 \mathrm{~cm}^{-1}$, towards the edge of the mid-IR, where the opacity of the beam-splitting filter increased, this increased to $\pm 1 \times 10^{-20} \mathrm{~cm}^{2}$ molecule ${ }^{-1}$ per $1 \mathrm{~cm}^{-1}$ band. The average standard errors of the slopes obtained from the regression of absorbance vs. concentration for $\mathrm{NF}_{3}$ and $\mathrm{CFC}$ 115 at selected wavelengths (Eq. 1) were \pm 5 and $6 \%$, respectively. This results in an average overall spectral error of $\pm 6 \%(1 \sigma)$ in both cases. This is the average error of the integrated band cross section and is fairly uniform for the major bands.

As shown in Table 2, the intensities of the two main absorptions bands (840-960 and 970-1085 $\mathrm{cm}^{-1}$ ) of $\mathrm{NF}_{3}$ measured in the present work are 3 and $11 \%$ larger than those reported by Robson et al. (2006), with an average deviation of $29 \%$ over the minor bands and $4 \%$ across the entire spectrum. All differences excluding the minor bands in the region between 1085 and $1580 \mathrm{~cm}^{-1}$ are comfortably within the combined error of both experiments. In contrast, the intensities of the two main absorption bands are 79 and $39 \%$ larger than those reported by Molina et al. (1995). The minor bands in our spectrum are on average $32 \%$ larger, and the absorption intensity is $42 \%$ larger across the whole spectrum. These differences are greater than the combined error from both experiments. Explanations for the lower values reported by Molina et al. (1995) have been discussed by Robson et al. (2006).

Figure 3 shows that the intensity of the main CFC-115 absorption band $\left(1212-1265 \mathrm{~cm}^{-1}\right)$ measured in the present
Table 3. Integrated absorption cross sections of CFC-115 measured in the present study at $296 \pm 2 \mathrm{~K}$ ( $1 \sigma$ uncertainty $\pm 6 \%$ for the major bands), and compared to the previous study of McDaniel et al. (1991).

\begin{tabular}{lcc}
\hline $\begin{array}{l}\text { Band limits/ } \\
\mathrm{cm}^{-1}\end{array}$ & $\begin{array}{c}\text { Integrated IR band } \\
\text { cross section/ } \\
10^{-17} \mathrm{~cm}^{2} \mathrm{molec}^{-1} \mathrm{~cm}^{-1}\end{array}$ & $\begin{array}{c}\text { Ratio to } \\
\text { integrated } \\
\text { cross section } \\
\text { from McDaniel } \\
\text { et al. (1991) }\end{array}$ \\
\hline $946-1020$ & 2.546 & 0.91 \\
$1105-1150$ & 2.015 & 0.94 \\
$1160-1212$ & 1.370 & 0.95 \\
$1212-1265$ & 5.381 & 0.94 \\
$1326-1368$ & 0.620 & 0.97 \\
\hline
\end{tabular}
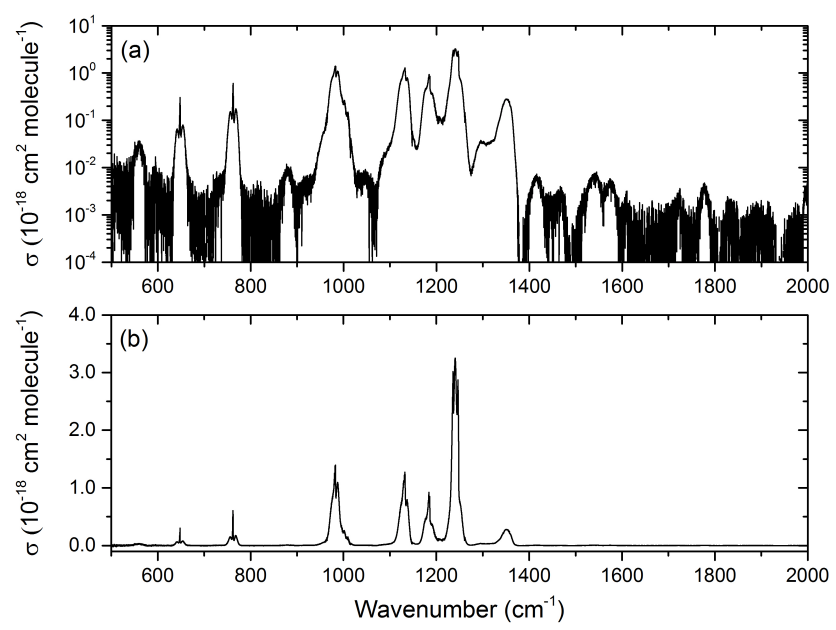

Figure 2. Infrared absorption spectrum of CFC-115 at $295 \pm 2 \mathrm{~K}$ on a logarithmic (a) and linear (b) scale. The logarithmic plot highlights the minor bands.

work is $6 \%$ smaller than that reported by McDaniel et al. (1991). The other significant bands at 946-1020, 1105$1150,1160-1212$ and $1326-1368 \mathrm{~cm}^{-1}$ are 9,6 and $3 \%$ smaller, respectively. These results are well within the combined error of both experiments.

\subsection{Atmospheric lifetimes}

The monthly averaged $\mathrm{NF}_{3}$ and $\mathrm{CFC}-115$ concentrations and loss rates in each WACCM grid box were used to estimate the atmospheric lifetimes of $\mathrm{NF}_{3}$ and $\mathrm{CFC}-115$, which were computed by dividing the global atmospheric burden of each compound by its integrated loss rate. The total loss rates were obtained from the sum of the individual loss rates due to photolysis, and reactions with mesospheric metals and with $\mathrm{O}\left({ }^{1} \mathrm{D}\right)$.

Figure $3 \mathrm{a}$ and $\mathrm{b}$ show the globally averaged profiles of the different modelled $\mathrm{NF}_{3}$ and CFC-115 tracers, which illus- 

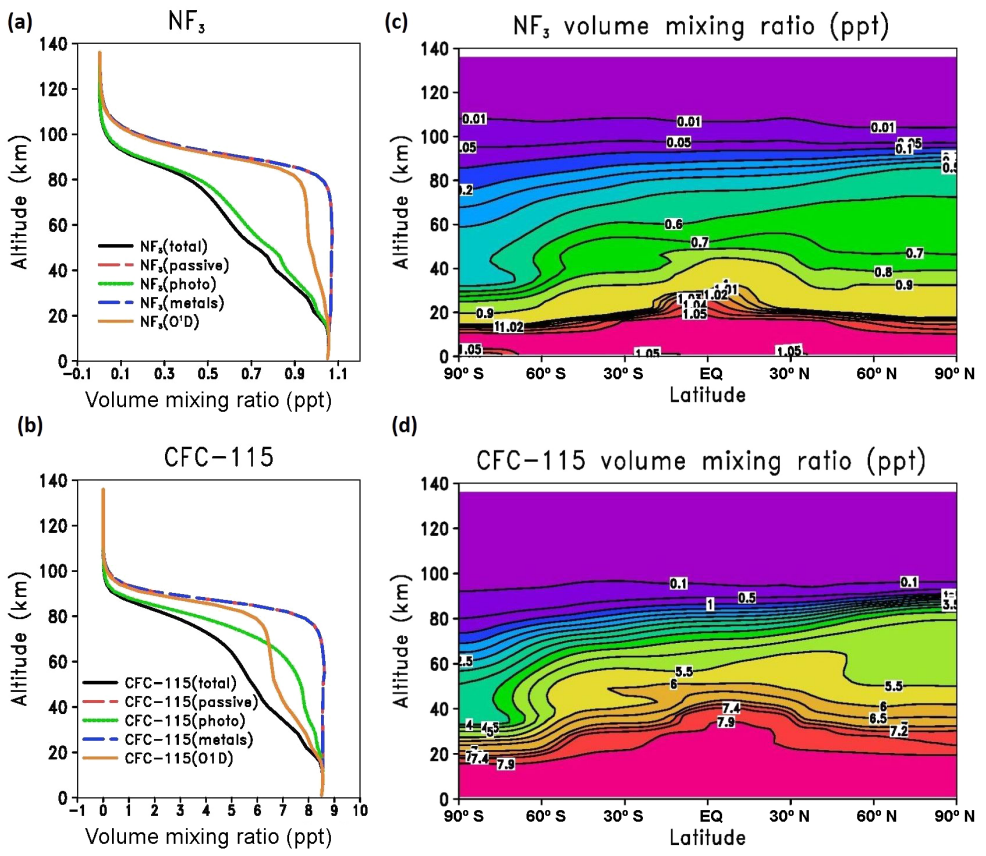

Figure 3. (a) Globally averaged $\mathrm{NF}_{3}$ mixing ratio in January of the thirteenth year of the WACCM simulation, illustrating the profiles of the four individual tracers (passive, photolysis, metal reaction and reaction with $\mathrm{O}\left({ }^{1} \mathrm{D}\right)$ ). (c) The corresponding zonal mean $\mathrm{NF}_{3}$ mixing ratio (ppt) as a function of altitude. (b) As (a) but for CFC-115. (d) As (c) but for CFC-115.

trate the impact of the different loss processes. The largest mixing ratio profiles for both $\mathrm{NF}_{3}$ and $\mathrm{CFC}-115$ are shown by the passive tracers as they are not subject to the removal processes. Note that the decay of the passive tracer mixing ratios above about $85 \mathrm{~km}$ is due to the very long timescale for the tracers to mix vertically into this region due to the dominance of molecular diffusion. Clearly, the reactions with atmospheric metals do not contribute to the atmospheric removal of these gases (i.e. the metal loss tracers profiles are almost identical to the passive profiles), and hence their impact on the lifetimes is negligible. The reason is that their temperature-dependent rate coefficients are much smaller than the rate coefficients of $\mathrm{O}\left({ }^{1} \mathrm{D}\right)$ reactions and also, as is shown in Fig. 11 in Totterdill et al. (2014) $\left(\mathrm{NF}_{3}\right)$ and in Fig. 9a in Totterdill et al. (2015) (CFC-115), the removal rates by mesospheric metals are 2 and 4 orders of magnitudes smaller for $\mathrm{NF}_{3}$ and CFC-115, respectively, than the removal rates by VUV (vacuum ultraviolet) photolysis, even at the peak of mesospheric metal layers $(90 \mathrm{~km})$. In contrast, photolysis and the reactions with atmospheric $\mathrm{O}\left({ }^{1} \mathrm{D}\right)$ are the dominant removal processes. Figure $3 \mathrm{c}$ and $\mathrm{d}$ are the corresponding monthly averaged zonal mean profiles of $\mathrm{NF}_{3}$ and CFC-115 from the surface up to $140 \mathrm{~km}$ in January. The surface mixing ratios of $\mathrm{NF}_{3}$ and $\mathrm{CFC}-115$ are 1.05 and 7.9 pptv, respectively. Both tracers are well mixed in the troposphere below $15 \mathrm{~km}$. There are sharp decreases in the tropical tropopause layer (TTL) $(12-17 \mathrm{~km})$. The mixing ratios of $\mathrm{NF}_{3}$ and $\mathrm{CFC}-115$ are decreasing with increasing altitude from the lower stratosphere to the mesosphere/lower thermosphere up to $90 \mathrm{~km}$. Above $90 \mathrm{~km}$, their mixing ratios are quite small $(<0.1 \mathrm{ppt}$ for both compounds). Around $40-50 \mathrm{~km}$ in the southern polar region, the low values of $\mathrm{NF}_{3}$ and CFC- 115 are caused by the removal of the reactions with $\mathrm{O}\left({ }^{1} \mathrm{D}\right)$.

Figure 4 shows the annual mean contributions of photolysis and reaction with $\mathrm{O}\left({ }^{1} \mathrm{D}\right)$ to the loss of $\mathrm{NF}_{3}$ and $\mathrm{CFC}-115$. The region of greatest loss is in the tropics, while at high latitudes the removal rates are orders of magnitude smaller. For both $\mathrm{NF}_{3}$ and CFC-115, the dominant region of photolysis is in the stratosphere, below $50 \mathrm{~km}$, although CFC-115 shows a weak secondary peak in photolytic loss over $60-80 \mathrm{~km}$, which is due to the increased photolysis loss rate of 2 orders of magnitude over this range (see Fig. 9b in Totterdill et al., 2014, 2015). Figure 5 is the annually averaged atmospheric lifetime for $\mathrm{NF}_{3}$ (for the run that does not include photolysis above $200 \mathrm{~nm}$ ) and CFC-115 as a function of simulation time. A steady state was assumed to be reached when the lifetime did not change more than $1 \%$ between consecutive years. The length of the model run is sufficient for the tracers to mix below $85 \mathrm{~km}$, where the dominant loss processes occur (Fig. 4). When photolysis at wavelengths $>200 \mathrm{~nm}$ is not included, the net lifetime is $(616 \pm 34)$ years as shown in Fig. 5. However, inclusion of photolysis above $200 \mathrm{~nm}$ reduces the mean lifetime of $\mathrm{NF}_{3}$ by $17 \%$ to $(509 \pm 21)$ years. This lifetime is $10 \%$ shorter than the recently published value of 569 years (SPARC, 2013). The uncertainties were 

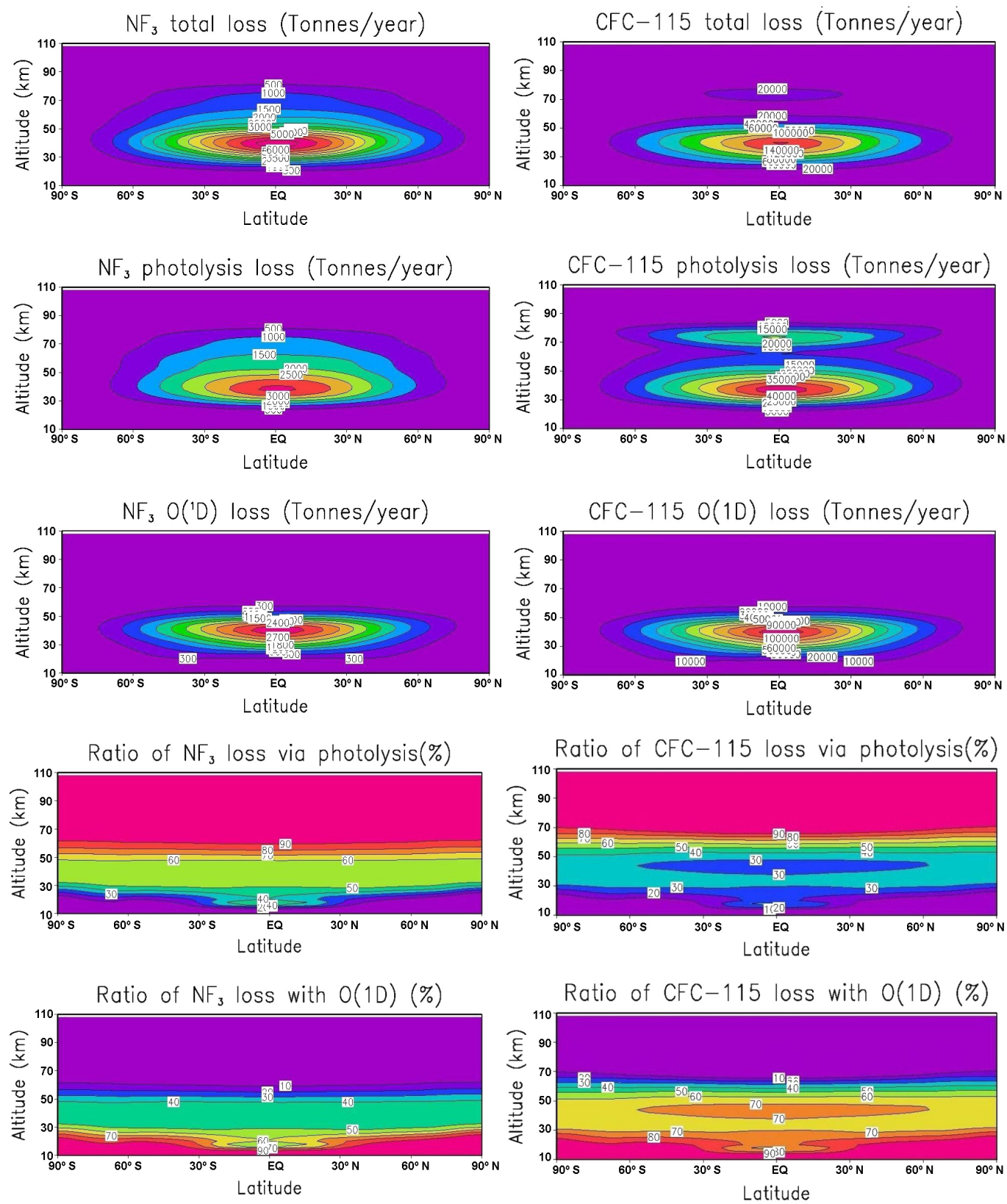

Figure 4. Atmospheric loss rates of the total $\mathrm{NF}_{3}$ (left-hand panels) and total CFC-115 (right-hand panels) showing the total loss rate, loss rates via photolysis and reaction with $\mathrm{O}\left({ }^{1} \mathrm{D}\right)$, and the percentage contributions to the total loss rates, in the thirteenth year of the simulation.

estimated from the error bars of the removal rate coefficients only (see Table 1), using the error propagation. Photolysis and reaction with $\mathrm{O}\left({ }^{1} \mathrm{D}\right)$ account for 67.7 and $32.3 \%$ of the global removal rate, respectively. The corresponding percentages from SPARC (2013) are 71.3 and $28.7 \%$. In the case of CFC-115, the lifetime in the present study is $(492 \pm 22)$ years, which is $9 \%$ smaller than the value of 540 years from SPARC (2013) and under half of that assumed in the GWP calculations of IPCC AR4 and IPCC AR5 (Forster et al., 2007; Myhre et al., 2013). Photolysis and reaction with $\mathrm{O}\left({ }^{1} \mathrm{D}\right)$ account for 34.4 and $65.6 \%$ of the global removal rate, respectively. Again, these are close to the corresponding percentages from SPARC (2013), which are 37.4 and $62.6 \%$. The differences between our results and those of SPARC (2013) likely arise from differences in the rates of atmospheric circulation in the 3-D WACCM and the 2-D model used in the SPARC report, as well as the implementation in WACCM of recently updated photolysis parameters (Totterdill et al., 2014, 2015). 
Table 4. Instantaneous and stratosphere-adjusted radiative forcings of $\mathrm{NF}_{3}$ and $\mathrm{CFC}-115$ in clear- and cloudy-sky conditions.

\begin{tabular}{lrrrrr}
\hline Molecule & \multicolumn{2}{c}{ Instantaneous } & & \multicolumn{2}{c}{ Adjusted } \\
\cline { 2 - 3 } \cline { 5 - 6 } & $\begin{array}{r}\text { Clear, } \\
10^{-4} \mathrm{~W} \mathrm{~m}^{-2}\end{array}$ & $\begin{array}{r}\text { All-sky, } \\
10^{-4} \mathrm{~W} \mathrm{~m}^{-2}\end{array}$ & & $\begin{array}{r}\text { Clear, } \\
10^{-4} \mathrm{~W} \mathrm{~m}^{-2}\end{array}$ & $\begin{array}{r}\text { All-sky, } \\
10^{-4} \mathrm{~W} \mathrm{~m}^{-2}\end{array}$ \\
\hline $\mathrm{NF}_{3}$ & 3.66 & 2.30 & & 4.18 & 2.61 \\
$\mathrm{CFC}-115$ & 27.70 & 18.09 & & 29.77 & 19.05 \\
\hline
\end{tabular}

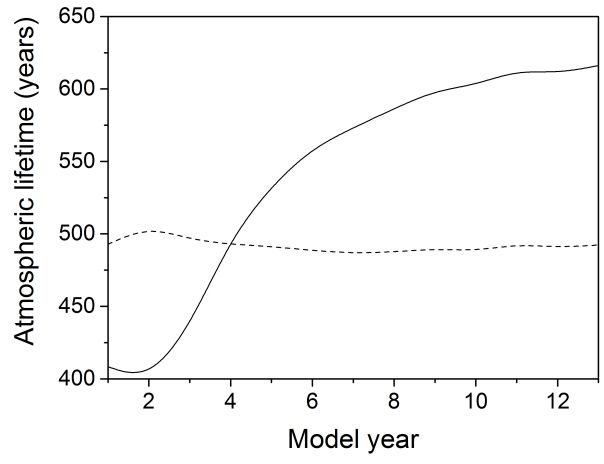

Figure 5. Annually averaged atmospheric lifetimes for $\mathrm{NF}_{3}$ (solid line) and CFC-115 (dashed line) as a function of simulation time.

\subsection{Calculation of radiative forcing and efficiencies}

The calculations of radiative forcing and radiative efficiencies (RE) are sensitive to several factors such as the choice of tropopause height and the way clouds are included in the model. This section examines these sensitivities and further examines the seasonal and latitudinal variations in forcing.

\subsubsection{Tropopause}

The definition of tropopause height directly influences the calculation of radiative forcing. There are three commonly used definitions: the thermal tropopause (ThT), defined as the lowest level at which the temperature lapse rate between this and all higher levels within $2 \mathrm{~km}$ falls below $2 \mathrm{~K} \mathrm{~km}^{-1}$ (WMO, 2007); the temperature minimum tropopause (TMT), the base of the stratospheric temperature inversion; and a uniform pressure level of $200 \mathrm{hPa}$ as a proxy for the top of the convective level, where there is a significant change in stability below the thermal tropopause (Forster and Shine, 1997). Forster and Shine (1997) identified the latter as the most appropriate for radiative forcing calculations at high horizontal resolution. However, the thermal tropopause (ThT) used in this study was found to generate results which were accurate to within $0.5 \%$ of those produced by the convective tropopause (Freckleton et al., 1998). At lower horizontal resolution this uncertainty is greater.

The temperature profile, and thus tropopause height, show a significant spatial variation and are affected by profile averaging. This adds extra inaccuracies when using a global an- nual mean profile, which does not account for the variation in tropopause height. This effect was explored with respect to the instantaneous radiative forcing of $\mathrm{NF}_{3}$. Figure 7 shows the latitudinal variation of instantaneous radiative forcing with tropopause height when using the ThT, TMT and globally averaged tropopause definitions. The globally averaged thermal tropopause was found to be $12.8 \mathrm{~km}$. When the spatially varying thermal tropopause was applied to the forcing calculations it yielded an average instantaneous radiative forcing $10 \%$ lower than that employing the ThT. The globally averaged TMT was found to be $14.9 \mathrm{~km}$. When this was applied it resulted in an average instantaneous radiative forcing $5 \%$ higher than the ThT. The spatially averaged TMT was found to be $3 \%$ higher on average, compared to its global averaged profile.

The global mean TMT gives a significant overestimation of radiative forcing from a high, unrepresentative tropopause of $14.9 \mathrm{~km}$ caused by temperature variations being smoothed out through averaging. Additionally, the averaging procedure affects parameters such as the $\mathrm{H}_{2} \mathrm{O}$ vapour and $\mathrm{O}_{3}$ profiles, so that averaging monthly profiles over latitudes representing the topics and midlatitudes (rather than globally) gives a better representation of these variables. Because both $\mathrm{NF}_{3}$ and CFC-115 are well mixed in the stratosphere, they are potentially less affected by tropopause height than species that decay strongly in the lower stratosphere (Myhre et al., 1998). Consequently, the spatially averaged ThT was selected for the calculations described below.

\subsubsection{Seasonal-latitudinal variation}

Figure 7 shows the large seasonal-latitudinal impact on variation in the IRF and RF of $\mathrm{NF}_{3}$ and CFC-115 under clearsky conditions. The latitudinal variation in zonally averaged forcing in a single month can be a factor of 8 ; the variation in monthly forcing for a single latitude is much smaller, approximately a factor of 2 on average. The lack of uniformity across this grid demonstrates the requirement for higher resolution calculations.

The variation of radiative forcing and efficiency as a function of latitude is primarily due to changes in the Planck function caused by variation in background temperature. Differences in cloudiness and $\mathrm{H}_{2} \mathrm{O}$ density levels were also found to contribute. Forcings averaged across the Southern Hemisphere were approximately $25 \%$ lower than those averaged 

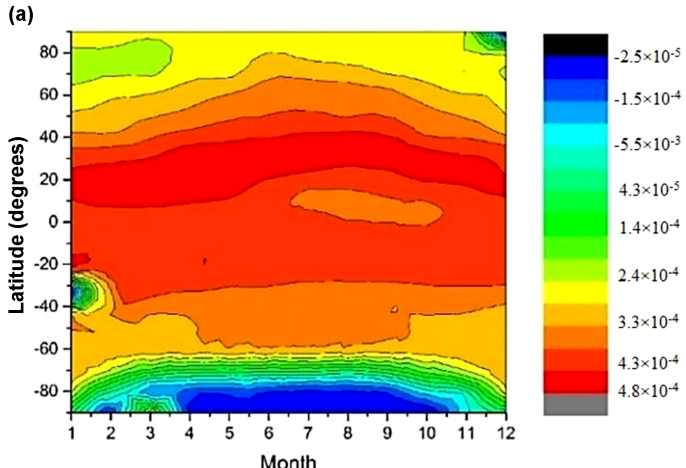

(c)

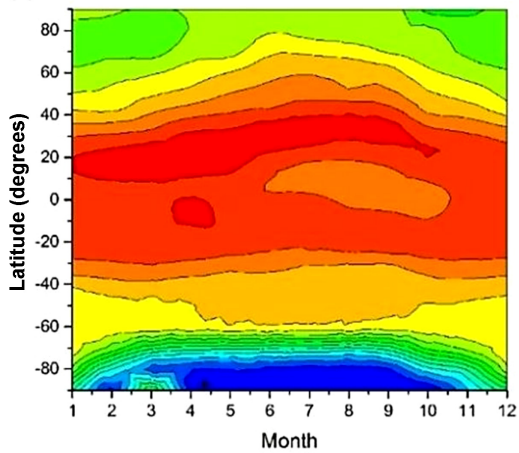

(b)

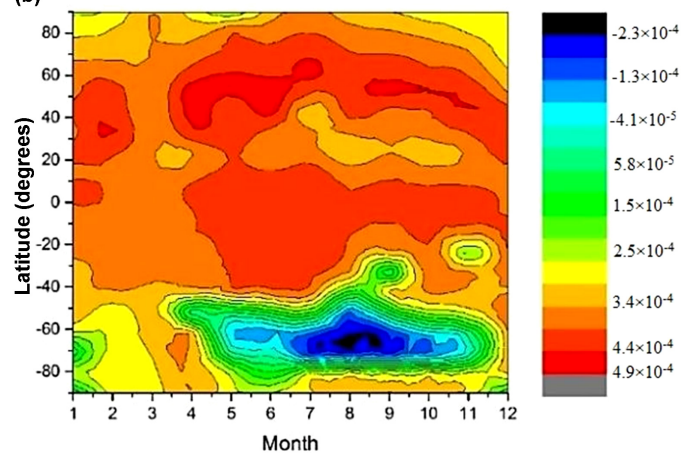

(d)
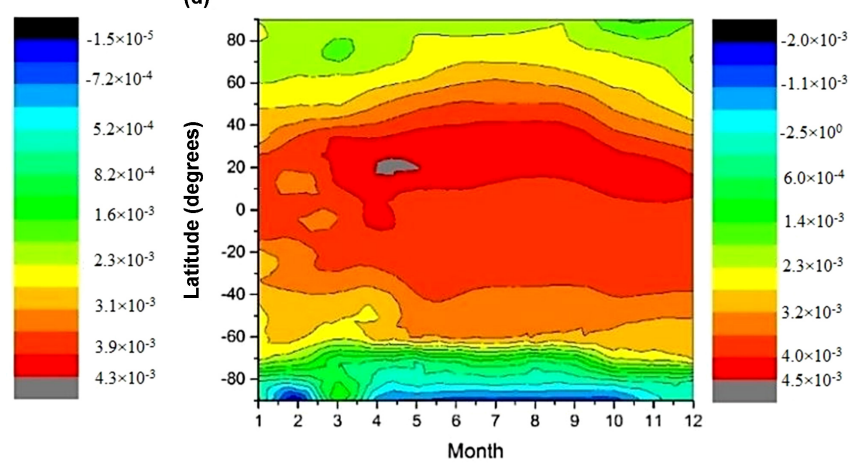

Figure 6. Contour plots for radiative forcing $\left(\mathrm{W} \mathrm{m}^{-2}\right)$ by latitude and month for (a) instantaneous radiative forcing of $\mathrm{NF}_{3}$, (b) stratospheric adjusted radiative forcing of $\mathrm{NF}_{3}$, (c) instantaneous radiative forcing of $\mathrm{CFC}-115$ and (d) stratospheric adjusted radiative forcing of $\mathrm{CFC}-115$. Note different contour intervals between panels.

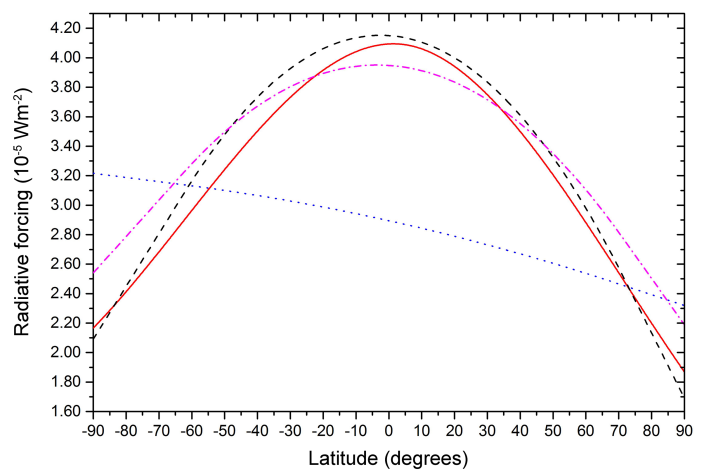

Figure 7. Variation of instantaneous radiative forcing for $\mathrm{NF}_{3}$ $\left(\mathrm{W} \mathrm{m}^{-2}\right)$ with tropopause height for four profiles: thermal tropopause (red solid line), average thermal tropopause (black dashed line), temperature minimum tropopause (dash dot magenta line) and average temperature minimum tropopause (blue dotted line).

across the Northern Hemisphere due to its average cooler surface temperature (Prather and Hsu, 2008). The lowest radiative forcings for each month are observed at the South Pole due to its cold surface temperature, with the very lowest occurring at the winter Antarctic polar vortex.

\subsubsection{Cloudiness}

Because clouds absorb across the same spectral region as $\mathrm{NF}_{3}$ and $\mathrm{CFC}-115$, their presence will cause a reduction in radiative forcing. Consideration of cloud coverage is therefore crucial to forcing calculations. The treatment of clouds involves determination of cloud band transmittance from user specified liquid water path, effective radius and cloud fraction at each altitude level. The zonal mean coverage for a given latitudinal band is obtained as monthly means from the International Satellite Cloud Climatology Project (ISCCP) D2 dataset averaged from between 1983 and 2008 (Rossow et al., 1996). Results were calculated from different, weighted combinations of clear sky plus various configurations of cloud coverage using the independent pixel approximation in libRadtran.

The IRF and RF in clear- and cloudy-sky conditions for $\mathrm{NF}_{3}$ and $\mathrm{CFC}-115$ are given in Table 4, and the relative radiative efficiencies in Table 5. Radiative forcings are shown in Fig. 6. For completeness, clouds and stratospheric adjustment need to be included in the overall estimate of radiative forcing and radiative efficiencies. Our best estimate of the all-sky adjusted radiative efficiency for $\mathrm{NF}_{3}$ is $0.25 \mathrm{~W} \mathrm{~m}^{-2} \mathrm{ppb}^{-1}$, approximately $25 \%$ larger than the $0.2 \mathrm{~W} \mathrm{~m}^{-2} \mathrm{ppb}^{-1}$ quoted in Myhre et al. (2013), and 
Table 5. Instantaneous and stratosphere-adjusted radiative efficiencies of $\mathrm{NF}_{3}$ and $\mathrm{CFC}-115$ in clear- and cloudy-sky conditions.

\begin{tabular}{lccccc}
\hline Molecule & \multicolumn{2}{c}{ Instantaneous } & & \multicolumn{2}{c}{ Adjusted } \\
\cline { 2 - 3 } \cline { 5 - 6 } & $\begin{array}{c}\text { Clear, } \\
\mathrm{W} \mathrm{m}^{-2} \mathrm{ppb}^{-1}\end{array}$ & $\begin{array}{c}\text { All-sky, } \\
\mathrm{W} \mathrm{m}^{-2} \mathrm{ppb}^{-1}\end{array}$ & & $\begin{array}{c}\text { Clear, } \\
\mathrm{W} \mathrm{m}^{-2} \mathrm{ppb}^{-1}\end{array}$ & $\begin{array}{c}\text { All-sky, } \\
\mathrm{W} \mathrm{m}^{-2} \mathrm{ppb}^{-1}\end{array}$ \\
\hline $\mathrm{NF}_{3}$ & 0.35 & 0.22 & & 0.40 & 0.25 \\
$\mathrm{CFC}-115$ & 0.32 & 0.20 & & 0.35 & 0.21 \\
\hline
\end{tabular}

Table 6. Comparison of the 20-, 100- and 500-year global warming potentials for $\mathrm{NF}_{3}$ and CFC-115 from this work, the IPCC AR4 (Forster et al., 2007) and the IPCC AR5 (Myhre et al., 2013).

\begin{tabular}{|c|c|c|c|c|c|c|c|c|}
\hline \multirow[b]{2}{*}{ Molecule } & \multicolumn{3}{|c|}{ This work } & \multicolumn{3}{|c|}{ IPCC AR4 } & \multicolumn{2}{|c|}{ IPCC AR5 } \\
\hline & $\mathrm{GWP}_{20}$ & $\mathrm{GWP}_{100}$ & $\mathrm{GWP}_{500}$ & $\mathrm{GWP}_{20}$ & $\mathrm{GWP}_{100}$ & $\mathrm{GWP}_{500}$ & $\mathrm{GWP}_{20}$ & $\mathrm{GWP}_{100}$ \\
\hline $\mathrm{NF}_{3}$ & 15600 & 19700 & 19700 & $12300^{\mathrm{a}}$ & $17200^{\mathrm{a}}$ & $20700^{\mathrm{a}}$ & $12800^{\mathrm{c}}$ & $16100^{c}$ \\
\hline CFC-115 & 6030 & 7570 & 7480 & $5310^{\mathrm{b}}$ & $7370^{\mathrm{b}}$ & $9990^{\mathrm{b}}$ & $5860^{\mathrm{d}}$ & $7670^{\mathrm{d}}$ \\
\hline
\end{tabular}

${ }^{a}$ Based on an atmospheric lifetime of 740 years. ${ }^{b}$ Based on an atmospheric lifetime of 1700 years. ${ }^{c}$ Based on an atmospheric lifetime of 500 years. ${ }^{\mathrm{d}}$ Based on an atmospheric lifetime of 1020 years.

also larger than the $0.21 \mathrm{~W} \mathrm{~m}^{-2} \mathrm{ppb}^{-1}$ estimated in Robson et al. (2006). These differences can be attributed to the larger absorption cross section present in our study (Table 2). The equivalent all-sky-adjusted RE for CFC-115 $\left(0.21 \mathrm{~W} \mathrm{~m}^{-2} \mathrm{ppb}^{-1}\right)$ is very similar to that quoted in Myhre et al. (2013). The globally averaged adjusted all-sky radiative forcings of $\mathrm{NF}_{3}$ and $\mathrm{CFC}-115$ are $2.6 \times 10^{-4} \mathrm{~W} \mathrm{~m}^{-2}$ and $19 \times 10^{-4} \mathrm{~W} \mathrm{~m}^{-2}$ respectively. Tables 4 and 5 also indicate that radiative forcings and efficiencies are about $60 \%$ larger if clouds are neglected. This is because a cloud acts a black body, and so the contribution to the total forcing from greenhouse gas changes situated below clouds is minimal. Thus, the optical depth due to the greenhouse species, as well as temperature difference between the emitting surface and the top of the atmosphere, and the region in which the greenhouse species absorbs, are much smaller where clouds are present (Myhre et al., 1998). The impact of cloud on both $\mathrm{NF}_{3}$ and CFC-115 is similar; because they are both very long-lived species, they are both well mixed in the stratosphere, and so the magnitude of downward irradiance due to each species at the tropopause is approximately the same.

\subsection{Global warming potentials}

Global warming potential is defined by the expression

$\mathrm{GWP}=\frac{\int_{0}^{\mathrm{TH}} a_{\chi}[\chi(t)] \mathrm{d} t}{\int_{0}^{\mathrm{TH}} a_{r}[r(t)] \mathrm{d} t}$,

where TH is time horizon; $a_{\chi}$ is radiative forcing due to a unit increase in atmospheric abundance of the compound $\left(\mathrm{W} \mathrm{m}^{-2} \mathrm{~kg}^{-1}\right.$ ) and $[\chi(t)]$ is its time-dependent decay in con- centration following its instantaneous release at time $t=0$. The denominator contains the corresponding quantities for $\mathrm{CO}_{2}$ as a reference gas (Myhre et al., 2013). GWP is the most common metric used by the WMO and IPCC to compare the potency of a greenhouse gas relative to an equivalent emission of $\mathrm{CO}_{2}$ over a set time period. GWP takes into account species lifetime. This means that a species with a very high radiative forcing may still have a low GWP if it also has a short atmospheric lifetime. Note that GWP is only one of a range of possible metrics and is not necessarily representative of temperature changes or other climate impacts, since it does not account for factors such as changes in emission or the introduction of replacement species. Other criticisms are also discussed in greater detail by Myhre et al. (2013).

Table 6 lists the 20-, 100- and 500-year GWPs based on cloudy-sky-adjusted radiative efficiencies of $\mathrm{NF}_{3}$ and CFC115 compared with the values reported in IPCC AR4 and AR5 (Forster et al., 2007; Myhre et al., 2013). The GWPs for $\mathrm{NF}_{3}$ are estimated to be 15600,19700 and 19700 over 20-, 100- and 500 years, respectively. These GWPs are considerably larger than quoted in IPCC AR5 due to the stronger absorption cross section and radiative efficiency of $\mathrm{NF}_{3}$. The GWPs for CFC-115 are 6030, 7570 and 7480 over 20-, 100and 500 years, respectively. The forcing efficiencies determined in the present study are much higher for $\mathrm{NF}_{3}$ but the same for CFC-115, when compared to IPCC AR5 (Myhre et al., 2013). The effect of the change in radiative efficiency is most obvious for the 20-year GWP, where, because the atmospheric lifetimes of $\mathrm{NF}_{3}$ and $\mathrm{CFC}-115$ are respectively 509 and 492 years, the species do not have time for significant loss to occur. In contrast, the 500-year GWP is more representative of the impact of the reduced lifetimes.

The trade-off between these competing effects is demonstrated in Table 6, where $\mathrm{NF}_{3}$ and CFC-115 exhibit 20- 
year GWPs larger by 27 and $14 \%$, respectively, than their IPCC AR4 determined values. These differences then decrease for the 100-year GWP (14 and $2 \%$ ) and the 500-year GWP ( -4 and $-25 \%)$. Note that in the case of CFC-115, where the IPCC AR4 atmospheric lifetime used to define the GWP is 1700 years, which is over 3 times that of our value of 492 years, the 500-year GWPs from Forster et al. (2007) are larger than our quoted values.

\section{Summary and conclusions}

In this study we have presented updated values for the IR absorption cross sections and atmospheric lifetimes of $\mathrm{NF}_{3}$ and CFC-115, as well as radiative forcing and radiative efficiencies, taking into account stratospheric adjustment and cloudy skies. These values have then been used to obtain values for the 20-, 100- and 500-year GWPs of both species. A sensitivity analysis for the forcing calculations relating to tropopause definition and grid resolution has also been provided.

The IR cross sections measured in the present study are larger than previously reported for $\mathrm{NF}_{3}$. These larger cross sections and possible differences in radiative transfer result in radiative efficiencies that are approximately $25 \%$ larger than those reported in IPCC AR5 for $\mathrm{NF}_{3}$. Atmospheric lifetimes of $(509 \pm 21)$ years and $(492 \pm 22)$ years have been determined for $\mathrm{NF}_{3}$ and $\mathrm{CFC}-115$, respectively, using the Whole Atmosphere Community Climate Model (WACCM). Model diagnostics confirm that CFC-115 is removed faster than $\mathrm{NF}_{3}$ in the atmosphere, except in the altitude region of $50-75 \mathrm{~km}$, where photolysis is the dominant removal process. Photolysis is the dominant loss process for $\mathrm{NF}_{3}$ loss $(67.7 \%)$, while for $\mathrm{CFC}-115$ the reaction with $\mathrm{O}\left({ }^{1} \mathrm{D}\right)$ dominates $(65.6 \%)$. Our overall lifetimes for the two gases are similar (within $10 \%$ ) to those reported in the recent SPARC (2013) assessment, but the contribution from the loss via photolysis is less in the case of $\mathrm{NF}_{3}$. Photolysis at wavelengths $>200 \mathrm{~nm}$ causes $17 \%$ reduction in the $\mathrm{NF}_{3}$ global lifetime.

Our model results show that omitting the stratospheric adjustment can result in an underestimation of radiative forcing of around 5-35\% and that omitting cloud can result in an overestimation of about $60 \%$ (Tables 4 and 5). These differences are a little higher than previous studies by Pinnock et al. (1995), who found an overestimation of 25$50 \%$ over several RF and IRF calculations for a range of hydro-halocarbons. Our results also show a strong variation of greenhouse gas forcings with season and latitude, varying by as much as several orders of magnitude. The lifetime results and IR absorption cross sections from the present study indicate global warming potentials (over a 500-year period) for $\mathrm{NF}_{3}$ and $\mathrm{CFC}-115$ of 19700 and 7480, respectively.

\section{Data availability}

WACCM (CESM) version 1.1.1 is available from http:// www.cesm.ucar.edu/models/cesm1.1/ or from W. Feng upon request.

\section{The Supplement related to this article is available online at doi:10.5194/acp-16-11451-2016-supplement.}

Acknowledgements. This work was part of the MAPLE project (NE/J008621/1) from the UK Natural Environment Research Council, which also provided a studentship for Anna Totterdill. We thank William Sturges (University of East Anglia) for supplying a sample of CFC-115 and Doug Kinnison (NCAR) for helping with WACCM simulations.

Edited by: J. B. Burkholder

Reviewed by: two anonymous referees

\section{References}

Arnold, T., Harth, C., Mühle, J., Kim, J., Salameh, P., Manning, A., Ivy, D., and Weiss, R.: Nitrogen trifluoride global emissions estimated from updated atmospheric measurements, P. Natl. Acad. Sci. USA, 110, 2029-2034, 2013.

Baasandorj, M., Fleming, E. L., Jackman, C. H., and Burkholder, J. B.: $O\left({ }^{1} \mathrm{D}\right)$ Kinetic Study of Key Ozone Depleting Substances and Greenhouse Gases, J. Phys. Chem. A, 117, 2434-2445, 2013.

Dillon, T. J., Horowitz, A., and Crowley, J. N.: Cross-Sections and Quantum Yields for the Atmospheric Photolysis of the Potent Greenhouse Gas Nitrogen Trifluoride, Atmos. Environ., 44, 1186-1191, 2010.

Dillon, T. J., Vereecken, L., Horowitz, A., Khamaganov, V., Crowley, J. N., and Lelieveld, J.: Removal of the Potent Greenhouse Gas $\mathrm{NF}_{3}$ by Reactions with the Atmospheric Oxidants $\mathrm{O}\left({ }^{1} \mathrm{D}\right)$, $\mathrm{OH}$ and $\mathrm{O}_{3}$, Phys. Chem. Chem. Phys., 13, 18600-18608, 2011.

Dudhia, A.: Reference Forward Model, RFM v4.34, National Centre for Earth Observation, University of Oxford, UK, 2014.

Edwards, D. P.: GENLN2: The new Oxford line-by-line atmospheric transmission/radiance model, Dept. of Atmospheric, Oceanic and Planetary Physics, Memorandum 87.2, University of Oxford, Oxford, UK, 1987.

Forster, P. M. and Shine, K. P.: Radiative Forcing and Temperature Trends from Stratospheric Ozone Changes, J. Geophys. Res., 108, 10841-10855, 1997.

Forster, P. M., Artaxo, P., Berntsen, T., Betts, R., Fahey, D. W., Haywood, J., Lean, J., Lowe, D. C., Myhre, G., Nganga, J., Prinn, R., Raga, G., Schulz, M., and Van Dorland, R.: Changes in Atmospheric Constituents and in Radiative Forcing, in: Climate Change 2007: The Physical Science Basis, Contribution of Working Group I to the Fourth Assessment Report of the Intergovernmental Panel on Climate Change, edited by: Qin, D., Manning, M., Chen, Z., Marquis, M., Averyt, K. B., Tignor, M., and Miller, H. L., Cambridge University Press, Cambridge, UK and New York, NY, USA, 2007. 
Freckleton, R. S., Highwood, E. J., Shine, K. P., Wild, O., Law, K. S., and Sanderson, M. G.: Greenhouse Gas Radiative forcing: Effects of Averaging and Inhomogeneities in Trace Gas Distribution, Q. J. Roy. Meteorol. Soc., 124, 2099-2127, 1998.

Garcia, R. R., Marsh, D. R., Kinnison, D. E., Boville, B. A., and Sassi, F.: Simulation of secular trends in the middle atmosphere, 1950-2003, J. Geophys. Res., 112, D09301, doi:10.1029/2006JD007485, 2007.

Kinnison, D. E., Brasseur, G. P., Walters, S., Garcia, R. R., Marsh, D. R., Sassi, F., Harvey, V. L., Randall, C. E., Emmons, L., Lamarque, J. F., Hess, P., Orlando, J. J., Tie, X. X., Randel, W., Pan, L. L., Gettelman, A., Granier, C., Diehl, T., Niemeier, U., and Simmons, A. J.: Sensitivity of chemical tracers to meteorological parameters in the MOZART-3 chemical transport model, J. Geophys. Res., 112, D20302, doi:10.1029/2006JD007879, 2007.

Kopp, G. and Lean, J. L.: A new, lower value of total solar irradiance: Evidence and climate significance, Geophys. Res. Lett., 38, L01706, doi:10.1029/2010GL045777, 2011.

Lamarque, J.-F., Emmons, L. K., Hess, P. G., Kinnison, D. E., Tilmes, S., Vitt, F., Heald, C. L., Holland, E. A., Lauritzen, P. H., Neu, J., Orlando, J. J., Rasch, P. J., and Tyndall, G. K.: CAM-chem: description and evaluation of interactive atmospheric chemistry in the Community Earth System Model, Geosci. Model Dev., 5, 369-411, doi:10.5194/gmd-5-369-2012, 2012.

Lean, J., Rottman, G., Harder, J., and Kopp, G.: SORCE contributions to new understanding of global change and solar variability, Sol. Phys., 230, 27-53, 2005.

Maione, M., Giostra, U., Arduini, J., Furlani, F., Graziosi, F., Lo Vullo, E., and Bonasoni, P.: Ten Years of Continuous Observations of Stratospheric Ozone Depleting Gases at Monte Cimone (Italy) - Comments on the Effectiveness of the Montreal Protocol from a Regional Perspective, Sci. Total Environ., 445, 155-164, 2013.

Marsh, D. R., Janches, D., Feng, W., and Plane, J. M. C.: A global model of meteoric sodium, J. Geophys. Res., 118, 11442-11452, 2013a.

Marsh, D. R., Mills, M. J., Kinnison, D. E., Lamarque, J.-F., Calvo, N., and Polvani, L. M.: Climate Change from 1850 to 2005 Simulated in CESM1(WACCM), J. Climate, 26, 7372-7391, $2013 \mathrm{~b}$.

Mayer, B. and Kylling, A.: Technical note: The libRadtran software package for radiative transfer calculations - description and examples of use, Atmos. Chem. Phys., 5, 1855-1877, doi:10.5194/acp-5-1855-2005, 2005.

McDaniel, A. H., Cantrell, C. A., Davidson, J. A., Shetter, R. E., and Calvert, J. G.: The Temperature Dependent, Infrared Absorption Cross Sections for the Chlorofluorocarbons: CFC-11, CFC-12, CFC-13, CFC-14, CFC-22, CFC-113, CFC-114, and CFC-115, J. Atmos. Chem., 12, 211-227, 1991.

Molina, L. T., Wooldridge, P. J., and Molina, M. J.: Atmospheric Reactions and Ultraviolet and Infrared Absorptivities of Nitrogen Trifluoride, Geophys. Res. Lett., 22, 1873-1876, 1995.

Myhre, G., Highwood, E. J., Shine, K. P., and Stordal, F.: New Estimates of Radiative Forcing Due to Well Mixed Greenhouse Gases, Geophys. Res. Lett., 25, 2715-2718, 1998.

Myhre, G., Shindell, D., Bréon, F.-M., Collins, W., Fuglestvedt, J., Huang, J., Koch, D., Lamarque, J.-F., Lee, D., Mendoza, B., Nakajima, T., Robock, A., Stephens, G., Takemura, T., and
Zhang, H.: Anthropogenic and Natural Radiative Forcing, in: Climate Change 2013: The Physical Science Basis, Contribution of Working Group I to the Fifth Assessment Report of the Intergovernmental Panel on Climate Change, edited by: Stocker, T. F., Qin, D., Plattner, G.-K., Tignor, M., Allen, S. K., Boschung, J., Nauels, A., Xia, Y., Bex, V., and Midgley, P. M., Cambridge University Press, Cambridge, UK and New York, NY, USA, 659740, doi:10.1017/CBO9781107415324.018, 2013.

NCAR/UCAR: CESM1.1 Series Public Release, http://www.cesm. ucar.edu/models/cesm1.1/, last access: September 2016.

Papadimitriou, V. C., McGillen, M. R., Fleming, E. L., Jackman, C. H., and Burkholder, J. B.: NF3: UV absorption spectrum temperature dependence and the atmospheric and climate forcing implications, Gephys. Res. Lett., 40, 440-445, doi:10.1002/grl.50120, 2013.

Pinnock, S., Hurley, M. D., Shine, K. P., Wallington, T. J., and Smyth, T. J.: Radiative Forcing of Climate by Hydrochlorofluorocarbons and Hydrofluorocarbons, J. Geophys. Res., 100, 23227-23238, 1995.

Plane, J. M. C., Feng, W., Dawkins, E., Chipperfield, M. P., Höffner, J., Janches, D., and Marsh, D. R.: Resolving the strange behavior of extraterrestrial potassium in the upper atmosphere, Geophys. Res. Lett., 41, 4753-4760, 2014.

Prather, M. J. and Hsu, J.: $\mathrm{NF}_{3}$, the Greenhouse Gas Missing from Kyoto, Geophys. Res. Lett., 35, L12810, doi:10.1029/2008GL034542, 2008.

Ramaswamy, V., Chanin, M.-L., Angell, J., Barnett, J., Gaffen, D., Gelman, M., Keckhut, P., Koshelkov, Y., Labitzke, K., Lin, J.-J. R., O’Neill, A., Nash, J., Randel, W., Rood, R., Shine, K., Shiotani, M., and Swinbank, R.: Stratospheric Temperature Trends: Observations and Model Simulations, Rev. Geophys., 39, 71122, 2001.

Robson, J. L., Gohar, L. K., Hurley, M. D., Shine, K. P., and Wallington, T. J.: Revised IR Spectrum, Radiative Efficiency and Global Warming Potential of Nitrogen Trifluoride, Geophys. Res. Lett., 33, L10817, doi:10.1029/2006GL026210, 2006.

Rossow, W. B., Walker, A. W., Beuschel, D. E., and Roiter, M. D.: International Satellite Cloud Climatology Project (ISCCP) Documentation of New Cloud Datasets, Rep. WMO/TDNo. 737, World Meteorological Organization, Geneva, Switzerland, 115 pp., 1996.

Rothman, L. S., Gordon, I. E., Babikov, Y., Barbe, A., ChrisBenner, D., Bernath, P. F., Birk, M., Bizzocchi, L., Boudon, V., Brown, L. R., Campargue, A., Chance, K., Cohen, E. A., Coudert, L. H., Devi, V. M., Drouin, B. J., Fayt, A., Flaud, J.-M., Gamache, R. R., Harrison, J. J., Hartmann, J.-M., Hill, C., Hodges, J. T., Jacquemart, D., Jolly, A., Lamouroux, J., LeRoy, R. J., Li, G., Long, D. A., Lyulin, O. M., Mackie, C. J., Massie, S. T., Mikhailenko, S., Müller, H. S. P., Naumenko, O. V., Nikitin, A. V., Orphal, J., Perevalov, V., Perrin, A., Polovtseva, E. R., Richard, C., Smith, M. A. H., Starikova, E., Sung, K., Tashkun, S., Tennyson, J., Toon, G. C., Tyuterev, V. G., and Wagner, G.: The HITRAN2012 molecular spectroscopic database, J. Quant. Spectrosc. Ra. Trans., 130, 4-50, 2013.

Sander, S. P., Friedl, R. R., Golden, D. M., Kurylo, M. J., Moortgat, G. K., Keller-Rudek, H., Wine, P. H., Ravishankara, A. R., Kolb, C. E., Molina, M. J., Finlayson-Pitts, B. J., Huie, R. E., and Orkin, V. L.: Chemical Kinetics and Photochemical Data for 
Use in Atmospheric Studies - JPL-Publication 10-6, California Institute of Technology, Pasadena, 2011.

Sherwood, S. C., Bony, S., Boucher, O., Bretherton, C., Forster, P. M., Gregory, J. M., and Stevens, B.: Adjustments in the ForcingFeedback Framework for Understanding Climate Change, B. Am. Meteorol. Soc., 96, 217-228, 2015.

Solomon, S., Qin, D., Manning, M., Alley, R. B., Berntsen, T., Bindoff, N. L., Chen, Z., Chidthaisong, A., Gregory, J. M., Hegerl, G. C., Heimann, M., Hewitson, B., Hoskins, B. J., Joos, F., Jouzel, J., Kattsov, V., Lohmann, U., Matsuno, T., Molina, M., Nicholls, N., Overpeck, J., Raga, G., Ramaswamy, V., Ren, J., Rusticucci, M., Somerville, R., Stocker, T. F., Whetton, P., Wood, R. A. and Wratt, D.: Technical Summary, in: Climate Change 2007: The Physical Science Basis, Contribution of Working Group I to the Fourth Assessment Report of the Intergovernmental Panel on Climate Change, edited by: Solomon, S., Qin, D., Manning, M., Chen, Z., Marquis, M., Averyt, K. B., Tignor, M., and Miller, H. L., Cambridge University Press, Cambridge, UK and New York, NY, USA, 2007.

SPARC: SPARC Report No. 6: Lifetimes of Stratospheric OzoneDepleting Substances, Their Replacements, and Related Species, in: SPARC Report, edited by: Ko, M. K. W., Newman, P. A., Reimann, S., and Strahan, S. E., 2013.
Totterdill, A., Gomez-Martin, J. C., Kovacs, T., Feng, W., and Plane, J. M. C.: Experimental study of the mesospheric removal of $\mathrm{NF}_{3}$ by neutral meteoric metals and Lyman- $\alpha$ radiation, J. Phys. Chem. A, 118, 4120-4129, 2014.

Totterdill, A., Kovacs, T., Martin, J. C. G., Feng, W. H., and Plane, J. M. C.: Mesospheric Removal of Very Long-Lived Greenhouse Gases $\mathrm{SF}_{6}$ and CFC-115 by Metal Reactions, Lyman-alpha Photolysis, and Electron Attachment, J. Phys. Chem. A, 119, 20162025, 2015.

Weiss, R. F., Muhle, J., Salameh, P. K., and Harth, C. M.: Nitrogen trifluoride in the global atmosphere, Geophys. Res. Lett., 35, L20821, doi:10.1029/2008GL035913, 2008.

WMO: Scientific Assessment of Ozone Depletion: 2006, Global Ozone Research and Monitoring Project Rep. 50, World Meteorological Organization, Geneva, Switzerland, 571 pp., 2007.

WMO: Scientific Assessment of Ozone Depletion: 2010, Global Ozone Research and Monitoring Project Rep. 52, World Meteorological Organization, Geneva, Switzerland, 516 pp., 2011. 